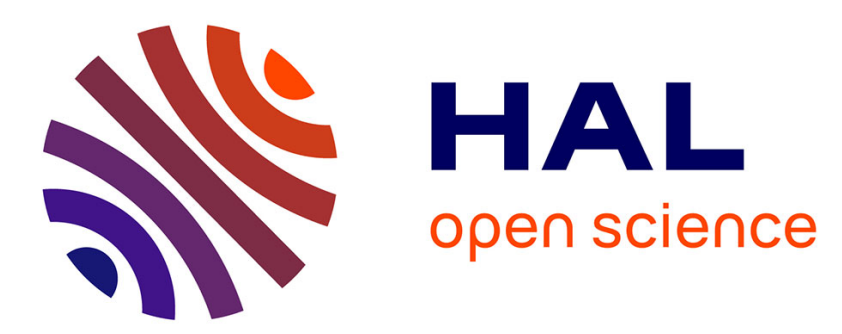

\title{
Influence of the voltage waveform and hydrostatic pressure on morphology and final length of discharges propagating over solid-liquid interfaces
}

Abderrahmane Beroual, Lazhar Kebbabi

\section{- To cite this version:}

Abderrahmane Beroual, Lazhar Kebbabi. Influence of the voltage waveform and hydrostatic pressure on morphology and final length of discharges propagating over solid-liquid interfaces. IEEE Transactions on Dielectrics and Electrical Insulation, 2009, 16 (6), pp.1574-1581. 10.1109/TDEI.2009.5361577 . hal-00443885

\section{HAL Id: hal-00443885 \\ https://hal.science/hal-00443885}

Submitted on 4 Jan 2010

HAL is a multi-disciplinary open access archive for the deposit and dissemination of scientific research documents, whether they are published or not. The documents may come from teaching and research institutions in France or abroad, or from public or private research centers.
L'archive ouverte pluridisciplinaire HAL, est destinée au dépôt et à la diffusion de documents scientifiques de niveau recherche, publiés ou non, émanant des établissements d'enseignement et de recherche français ou étrangers, des laboratoires publics ou privés. 


\title{
Influence of the Voltage Waveform and Hydrostatic Pressure on Morphology and Final Length of Discharges Propagating over Solid-liquid Interfaces
}

\author{
A. Beroual and L. Kebbabi \\ Ecole Centrale de Lyon, AMPERE Laboratory, CNRS UMR 5005, \\ 36 avenue Guy de Collongue 69134 Ecully Cedex, France
}

\begin{abstract}
This paper is aimed at the influence of the voltage waveform (lightning impulse, dc and ac) and hydrostatic pressure on the morphology and final length of creeping discharges propagating over solid / liquid insulating surfaces in a pointplane electrode arrangement. Different solid materials immersed in mineral oil are tested. It is shown that under ac and dc, the discharges do not present a radial shape as observed with the negative discharges under lightning impulse voltages. For a given solid sample, the final length $L_{f}$ (i.e. the maximum extension) of discharges is longer with ac than with lightning impulse voltage and dc. The currents waveforms are similar to those observed in liquids. On the other hand, the length of discharge branches is reduced when the hydrostatic pressure is increased whatever the voltage waveforms and polarity. $L_{f}$ increases quasilinearly with the voltage and decreases when the hydrostatic pressure is increased. And for given voltage and pressure, the thinner the solid sample and/or the higher its dielectric constant, the longer the discharges are, indicating the important role of capacitive effects in the propagation mechanisms of discharges.
\end{abstract}

Index Terms - Creepage discharge, propagation, interface phenomena, flashover.

\section{INTRODUCTION}

THE creeping discharges can be observed on the surface of some elements constituting the insulating systems of power transformers as the bushings or pressboards for instance when apparatus are submitted to critical electric fields induced by high voltage stresses (lightning impulse, switching impulse and over voltages). These can lead to the partial or total deterioration of insulation requiring the repairing of apparatus or even its replacement. Therefore, it is essential for the design and dimensioning of high voltage oil-filled apparatus in which these insulating structures are used (power transformers, capacitors, circuit breakers, etc.) to well understand the physicochemical processes responsible of the initiation and propagation of such discharges. This passes through the characterization of these discharges including their shape and velocity, the associated current (electrical charge) and the light they emit.

Numerous studies have been devoted to the morphology and the length of creeping discharges in normal conditions of pressure and temperature [1-6]. In previous work, we showed

Manuscript received on 10 October 2008, in final form 20 April 2009. that the creeping discharges initiated under negative lightning impulse voltage present a fractal dimension which depends on the physical and geometrical parameters of the solid insulators and more specifically on the thickness of solid samples and the dielectric constant of insulator [7]. The value of the density of branches also increases when the thickness of the solid insulating decreases $[7,8]$.

This paper deals with the influence of voltage waveforms (namely ac, dc and lightning impulse voltages) and hydrostatic pressure on the characteristic parameters of discharges propagating at solid/liquid insulating interfaces using a point-plane electrode arrangement. We especially analyze the morphology of these discharges and their final length versus the type of voltage and its polarity, the thickness and kind of solid insulator as well as the hydrostatic pressure.

\section{EXPERIMENTAL SET-UP}

The schematic diagram of the experimental setup is presented on Figure 1. It is similar to that we used in previous works [7, 8]. For the continuity, we recall here the main features of this setup. The test cell containing the solid/liquid system and the point- 
plane electrodes arrangement consists of a cylindrical core of 90 $\mathrm{mm}$ high and $110 \mathrm{~mm}$ inner diameter, and two flats and circular covers. The upper cover was of Plexiglas (transparent material) enabling to visualize the discharges and to support a point electrode; the lower one which constitutes also the electrode plane, was of brass. The point electrode was made of tungsten the radius tip of which is $10 \mu \mathrm{m}$. The cylindrical core of the test cell consists of two screwed parts: an upper part of $60 \mathrm{~mm}$ high made of Teflon and a bottom part issued from Plexiglas of $30 \mathrm{~mm}$ high. The contact between the point electrode and the solid samples is controlled by a CCD camera through the transparent part of the cylindrical core of the test cell.

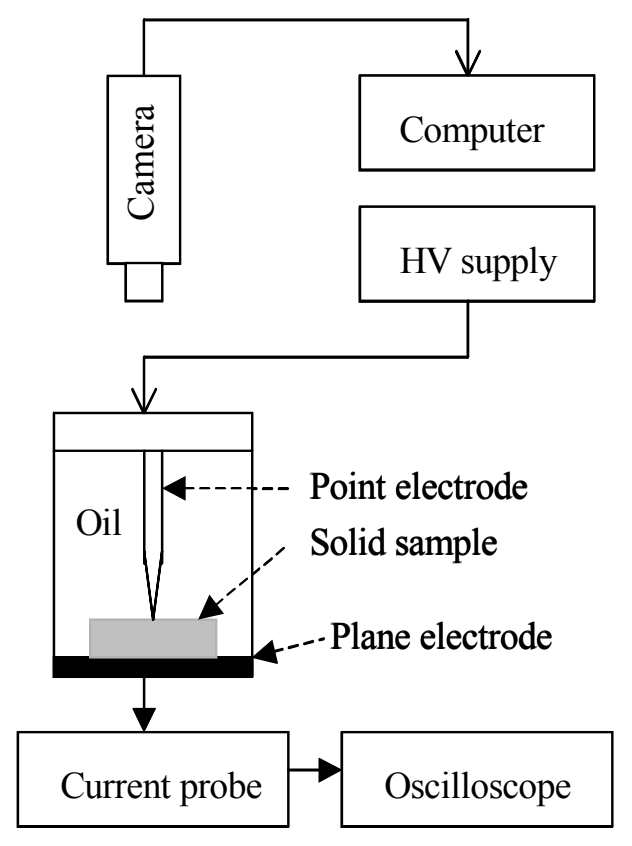

Figure 1. Scheme of the experimental set-up.

The solid insulating samples we inserted between the pointplane electrodes arrangement are discs of $100 \mathrm{~mm}$ diameter; their thickness varies between 2 and $30 \mathrm{~mm}$. The solid insulating samples we tested are issued from different materials: phenoplast resin (known as Bakelite), glass, polycarbonate, polyethylene and polypropylene. These samples are immersed in mineral oil (naphtenic type) which is filtered and degassed after each flashover. The solid samples are changed each time a flashover occurs or traces are observed on the solid surface.

The tests are achieved under ac, dc and lightning impulse voltage $(1.2 / 50 \mu \mathrm{s})$ supplied respectively by a HV transformer $(50 \mathrm{kV}, 50 \mathrm{~Hz})$, a dc generator $(200 \mathrm{kV}, 2 \mathrm{~mA})$ and a $200 \mathrm{kV}$ Marx generator.

The optical observation of discharges is based on the integrated images taken with the help of a CCD camera connected to a high performance video card. The CCD camera is a "SONY XC-HR58" type, high SVGA resolution (767x580 pixels) image capturing at a speed of 50 full frames/sec. It's set to record 900 images before stopping. The currents associated to the discharges are measured through a $50 \Omega$ non-inductive resistor connected in series with the test cell, and thanks to a high time resolution oscilloscope (Tektronix DSA 601A).

\section{EXPERIMENTAL RESULTS}

\subsection{INFLUENCE OF THE VOLTAGE WAVEFORM}

\subsubsection{INITIATION THRESHOLD VOLTAGE}

The initiation threshold voltage of discharges, $U_{0}$, depends upon the voltage waveform and the properties of insulator. Generally, $U_{0}$ is higher under dc than under ac and lightning impulse voltages. On the other hand, $U_{0}$ is higher with polycarbonate than with phenoplast resin and glass which have a highest dielectric constant. This is due to the electric field strength at the tip of point electrode which is all the more important as the difference of the permittivity between the solid insulating sample and oil $\left(\varepsilon_{r}=2.3\right)$ is high [8]. And the thicker the solid sample, the higher $U_{0}$.

\subsubsection{DISCHARGE PATTERNS}

The morphology of discharges greatly depends on the type and polarity of the voltage as well as the properties of solid and liquid materials constituting the interface.

\subsubsection{UNDER LIGHTNING IMPULSE VOLTAGE}

The discharges emanating from a negative point are radial with straight branches (Figure 2). Note that the photographs represent the maximum extension of discharges (i.e., the final length $L_{f}$ of discharges). The end of these branches and their ramifications constitutes a more or less circular contour, centred at the point. The surface density of branches, $\rho$, depends on the type of solid insulating and its thickness. For each oil/solid insulating interface, $\rho$ increases when the thickness of solid insulating is reduced and/or the dielectric constant of the solid insulator is increased. Contrary to the negative discharges, the positive ones do not present a radial shape. They are characterized by ramified branches ended by very luminous points at their extremities.

\subsubsection{UNDER AC}

The creeping discharges do not propagate radially. Some examples are shown on Figure 3 for samples of polycarbonate, glass and phenoplast resin. These discharges consist of a random number of main branches (or discharge feet) the number of which varies from one discharge to another one. However, the shapes of these discharges depend on the kind of solid insulator; the ramification number is higher for samples of Bakelite and glass than that one of polycarbonate. Note that the branches of discharges describe circular trajectories which seem turning around the 
point electrode and especially in the case of oil/polycarbonate.
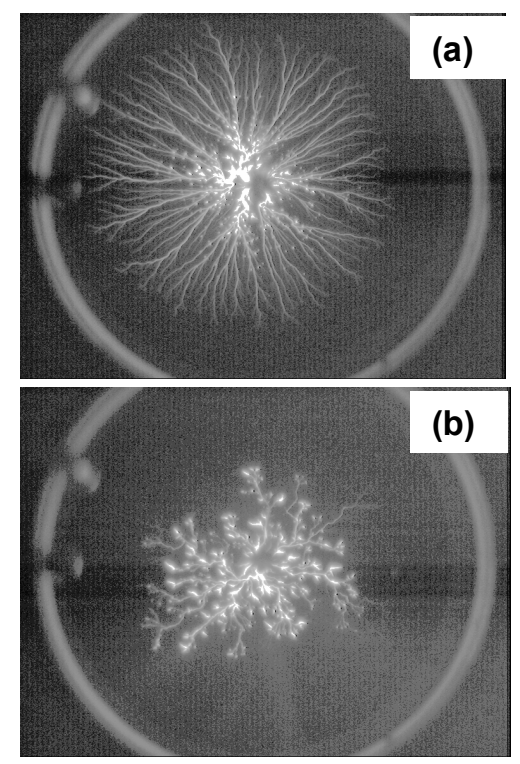

Figure 2. Photographs of negative (a) and positive (b) creeping discharges over Bakelite samples of $2 \mathrm{~mm}$ thickness, under lightning impulse voltage the crest value of which is $U_{\text {crest }}=40 \mathrm{kV}$.
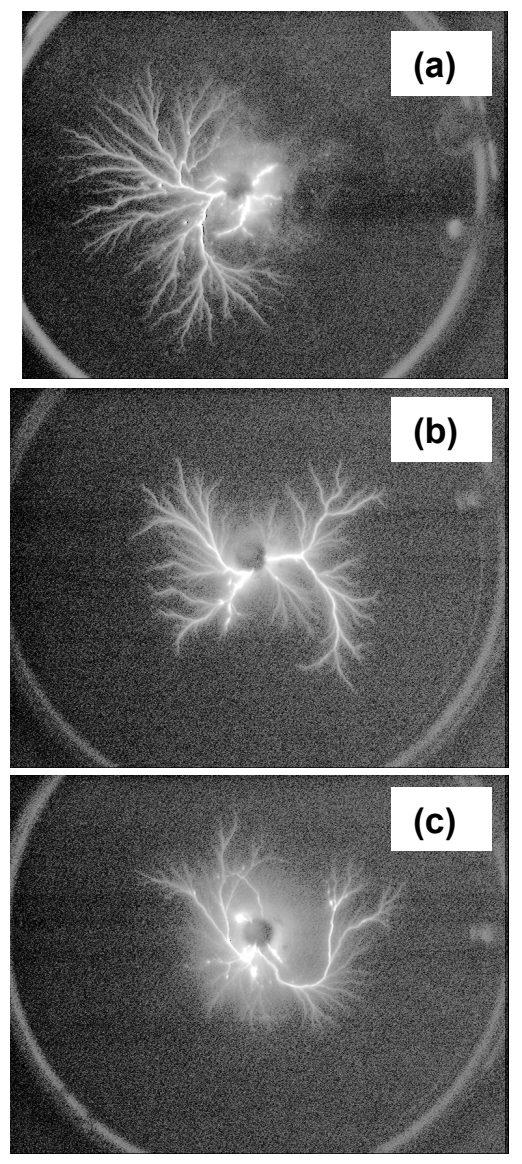

Figure 3. Typical photographs of creeping discharges over different solid samples of $5 \mathrm{~mm}$, under ac voltage: (a) Bakelite $-U=40 \mathrm{kV}$; (b) glass - $U=35$ $\mathrm{kV}$; and (c) polycarbonate $-U=40 \mathrm{kV}$.

\subsubsection{UNDER DC}

The discharges have some own characteristics (Figure 4). The branches number varies from one discharge to another one as with ac. The branches of the same discharge can have different lengths and the ends of branches don't necessarily form a circular contour as that characterising the radial discharges. At first sight, the distribution of branches seems disorderly; however we observed certain symmetry with regards to a virtual axis which passes through the point. The orientation of branches and their distribution over the surface of solid sample are influenced by the space charge. Note that under dc, it was not possible to observe creeping discharges over glass and other polymers as polycarbonate, polyethylene and polypropylene except some untimely discharges observed only with a positive point. The discharges we analysed are those observed over Bakelite and impregnated paper samples. When the voltage is increased over $120 \mathrm{kV}$, we observed either a flashover or a breakdown of insulator. This is due to the accumulation of injected charges on the insulator which leads to a fast increase of the electric potential. The whole voltage is practically applied at the solid sample.

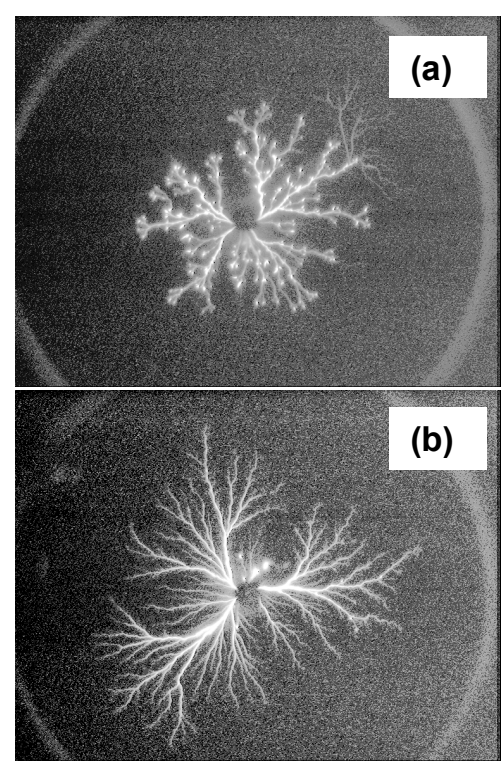

Figure 4. Typical photographs of creeping discharges over Bakelite sample of $2 \mathrm{~mm}$ thickness, under positive (a) and negative (b) dc voltage of $70 \mathrm{kV}$.

\subsubsection{FINAL LENGTH OF CREEPING DISCHARGES}

For a given solid sample, the final length $L_{f}$ of creeping discharges increases quasi-linearly with the voltage whatever the voltage waveform (Figures 5 to 7). However, $L_{f}$ is higher with ac than with lightning impulse voltage and dc. Consequently the flashover voltages are lower under ac than for the other voltage waveforms. This is of a great interest for the dimensioning of insulators. On the other hand, $L_{f}$ is greatly influenced by the thickness and dielectric constant of the solid insulating sample. The thinner the solid 
sample and/or the higher its dielectric constant, the longer the discharges are. Indeed, for a given value of the voltage, $L_{f}$ is higher with glass $\left(\varepsilon_{r}=5 ; \varepsilon_{r}\right.$ being the dielectric constant) and phenoplast resin $\left(\varepsilon_{r}=4.8\right)$ samples than with polycarbonate $\left(\varepsilon_{r}=2.9\right)$ samples. It appears from the above results that the capacitive effects play a fundamental role in the initiation and propagation mechanisms of creeping discharges.
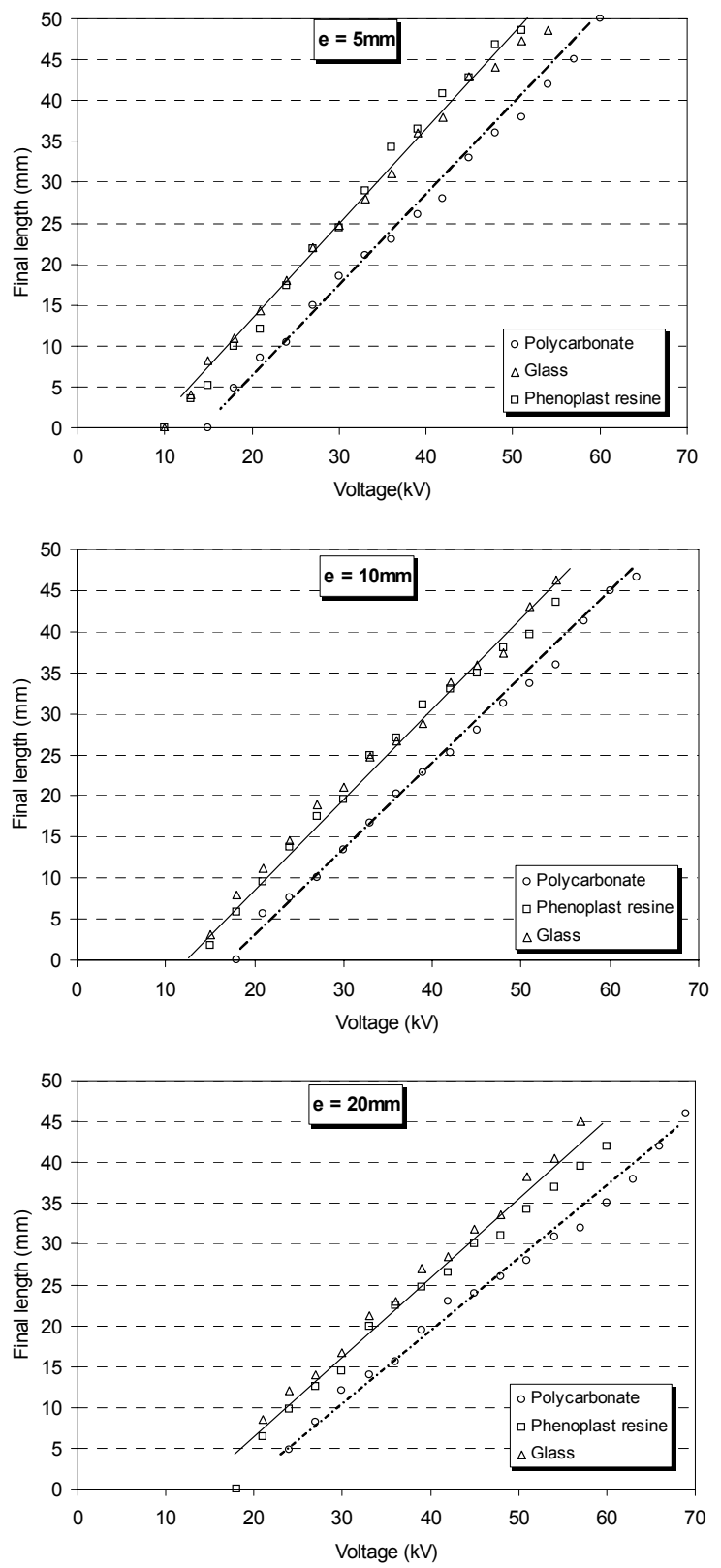

Figure 5. Final length $L_{f}$ of negative creeping discharges propagating over three kinds of solid samples versus the crest value of lightning impulse voltage $(1.2 / 50 \mu \mathrm{s})$ for different thicknesses of insulators.

Note that the average velocities of creeping discharges are of the same range as that measured in liquids [9]. The slope of the final length - voltage characteristics, $L_{f}=f(U)$, are of the same range for the three voltage waveforms. However, for a given crest value of voltage, $L_{f}$ is much higher for ac and lightning impulse voltages than that for dc, whatever the polarity of point electrode. The slopes $A$ of $L_{f}=f(U)$ depend upon the thickness, $e$, and the dielectric constant of solid samples. The higher $e$, the weaker the slope $A$ is. On the other hand, the characteristics $L_{f}(U)$ obtained with Bakelite and glass which are two materials having their dielectric constants very close $(\varepsilon r=4.8, \varepsilon r=5$, respectively), are quasiidentical. For ac and impulse voltages and a given $e$, they are lagged of about $5 \mathrm{kV}$ with regards to those obtained with polycarbonate $(\varepsilon r=2.9)$. For a given voltage, $L_{f}$ is clearly higher with samples of Bakelite and glass than with samples of polycarbonate.
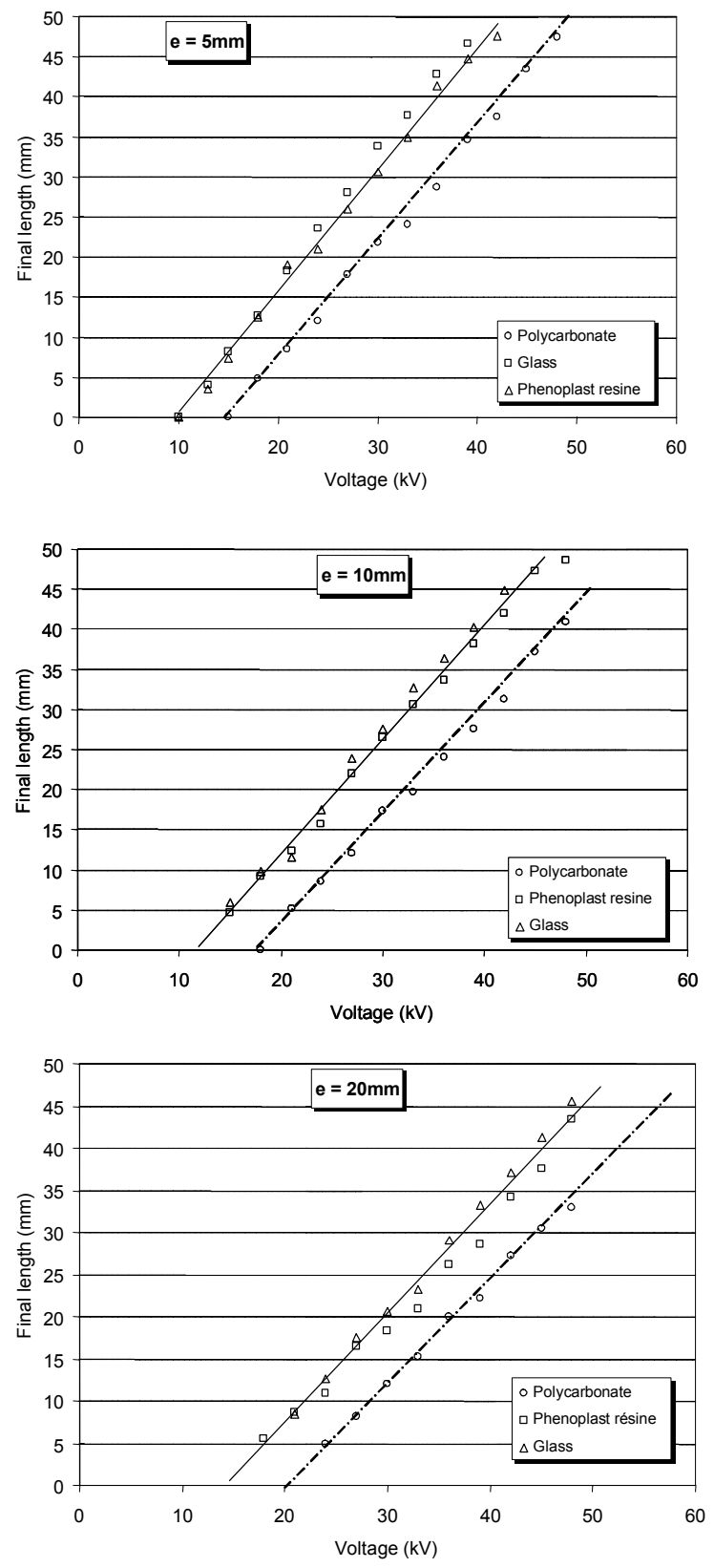

Figure 6. Final length $L_{f}$ of creeping discharges propagating over three kinds of solid samples versus ac voltage for different thicknesses of insulator. 

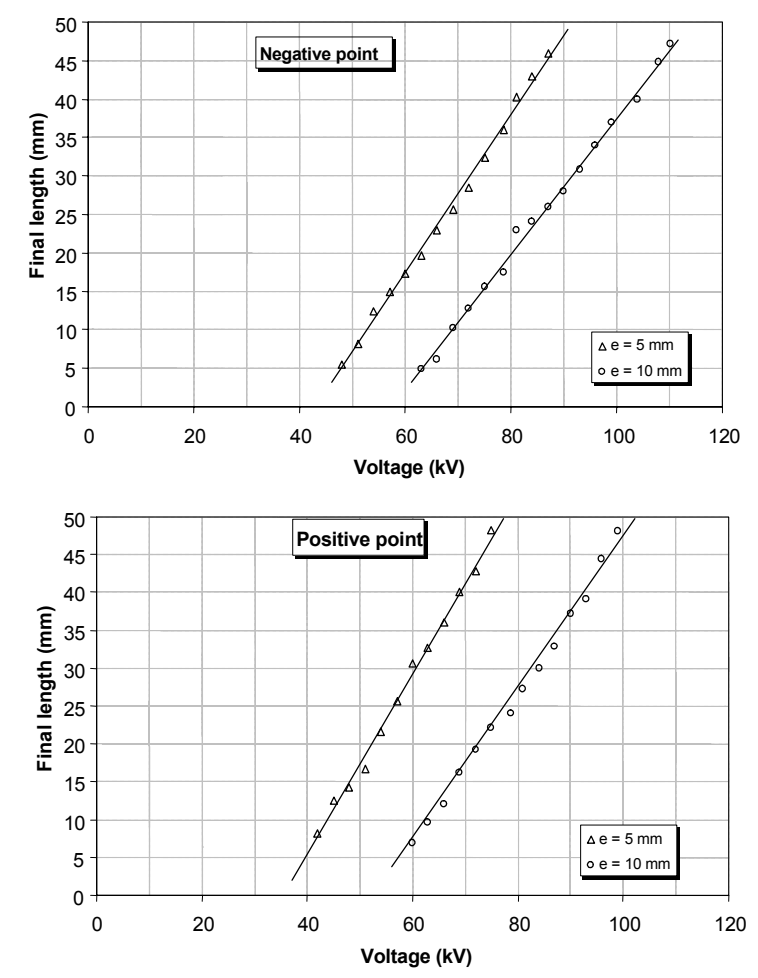

Figure 7. Final length $L_{f}$ of creeping discharges propagating over three kinds of solid samples versus negative and positive dc voltages for two thicknesses of insulator.

Note that the value of $L_{f}$ we reported on figures represents an average value on ten tests for a given voltage whatever the wave shape of voltage. We didn't represent the error bars to don't encumber the figures. On the other hand, under ac, the voltage is applied during 500 cycles corresponding to 10 seconds. To appreciate the appearance frequency of positive and negative discharges, we used a partial discharge detector and the results we obtained are analyzed using the $(\varphi q n)$ matrix (phase, charge, number) which is a visual representation of the number of discharges, the phase and the apparent charge generally used for partial discharge measurements. However, we plotted the value of the most extended discharge $L_{f}$ independently of the polarity. A similar procedure has been used to measure the discharge final length $L_{f}$ under dc voltage. However, due to the fact that the discharge number is lower when dc voltage is applied to a sample, the duration of a test in that case was extended to 1 minute.

\subsubsection{CURRENT}

The current waveform accompanying the creeping discharges are generally similar to those observed in liquids [9]. The associated currents to positive discharges present a continuous component on which is superimposed a series of impulses (Fig. 8); the amplitude of these currents increases with the voltage. And the currents associated to the negative ones consist of discrete pulses of a very high frequency. By increasing voltage, we observe the appearance of a continuous component.
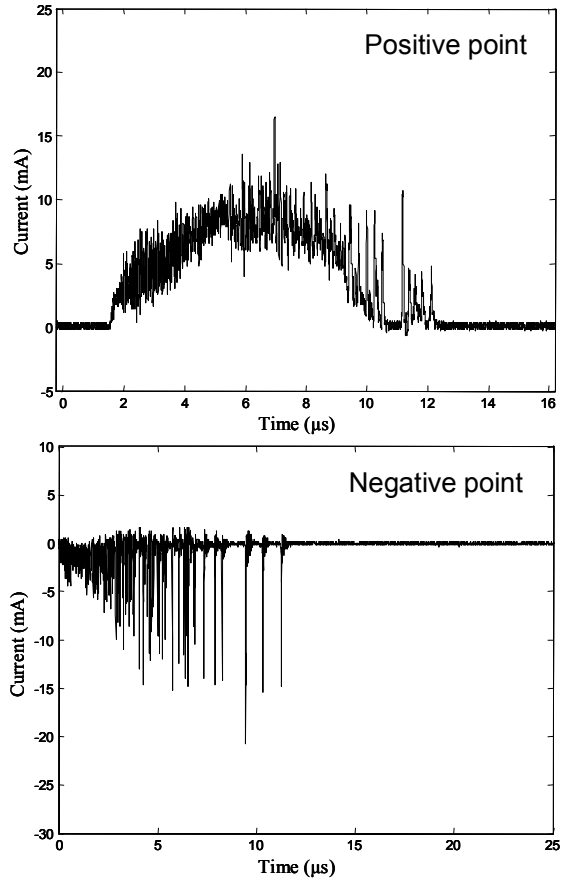

Figure 8. Currents of positive and negative creeping discharges propagating over Bakelite sample of $2 \mathrm{~mm}$ thickness, under dc voltage of $50 \mathrm{kV}$.

\subsection{INFLUENCE OF HYDROSTATIC PRESSURE}

\subsubsection{DISCHARGES MORPHOLOGY}

Figures 9 and 10 show the influence of pressure on the shape of discharges propagating at oil/bakelite interface under lightning impulse voltage for both negative and positive polarities. We observe that the length of discharge branches is reduced when the pressure is increased. Also, for a given voltage and thence a given shape of discharge, there is a pressure for which the discharge disappears. Similar effects of pressure have been observed with streamers initiated in liquids $[9,10]$. This indicates the presence of gaseous processes in the initiation and propagation mechanisms of creeping discharges.

This constitutes an important result for the industrial applications especially for tight apparatus since the increase of pressure significantly improves the dielectric strength of solid/liquid insulating system whatever the polarity of the voltage. Note that some discharges leave traces on the surface of insulators constituting preferential paths for some branches of the following discharges. For that purpose, the oil and solid samples are changed each time traces are observed.

As we observed at atmospheric pressure, the morphology of discharges differs depending on the polarity of the voltage [7]. Indeed, the radial aspect of negative creeping discharges is maintained even when a hydrostatic pressure is increased while the positive discharges are characterized by sinuous and ramified branches and don't present a radial shape. As concerns the influence of dielectric constant of solid insulators and their thickness, the 
comments we made at atmospheric pressure are valid when varying the pressure.
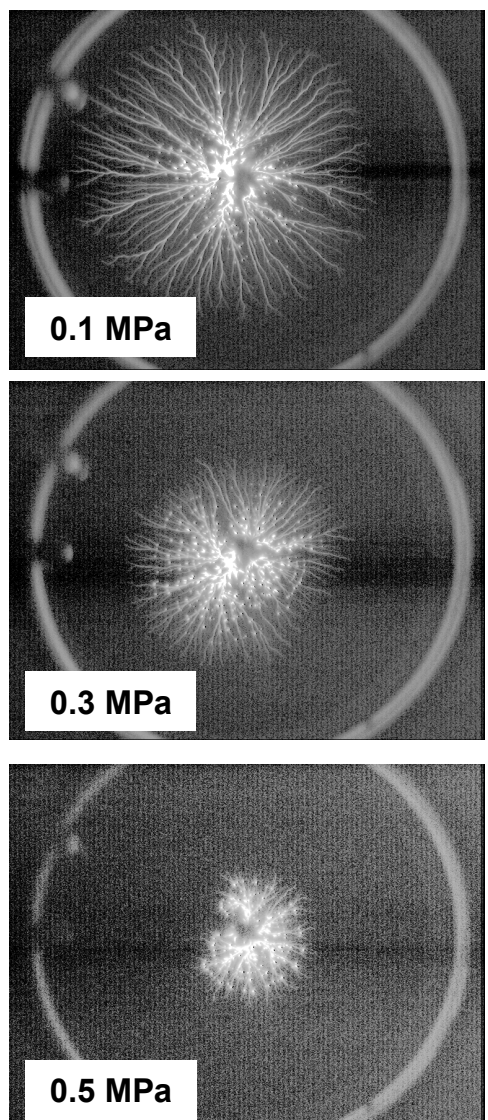

Figure 9. Photographs of negative creeping discharges propagating over Bakelite samples of $2 \mathrm{~mm}$ thickness for different values of hydrostatic pressure, the applied voltage being a lightning impulse the crest value of which is $U_{\text {crest }}=50 \mathrm{kV}$.

\subsubsection{FINAL LENGTH}

The final length $L_{f}$ of discharges is reduced when the hydrostatic pressure is increased (Figures 11 and 14). The final length - voltage $\left(L_{f}=f(U)\right)$ characteristics are straight lines the slopes of which depend on the applied pressure. The slopes $k_{v}$ are all the weaker as the pressure is high. From these characteristics, one can deduce the initiation threshold voltage $U_{0}$ of discharges, for given pressure $P$ and solid/liquid system, by extrapolation at $L_{f}=0 \mathrm{~mm}$. Note the values of $U_{0}$ we get by extrapolation are very close to those we measured using the detection of a current signal [8]. Thus, the $L_{f}=f(U)$ characteristics can be described by the following relationship

$$
L_{f}(U)=k_{v}\left(U-U_{0}\right)
$$

$k_{v}$ is a constant depending on both materials constituting the insulation system (solid/liquid). The threshold voltage $U_{0}$ over which a discharge is initiated varies with the pressure and the solid/liquid system. It is all the higher as the pressure is high.
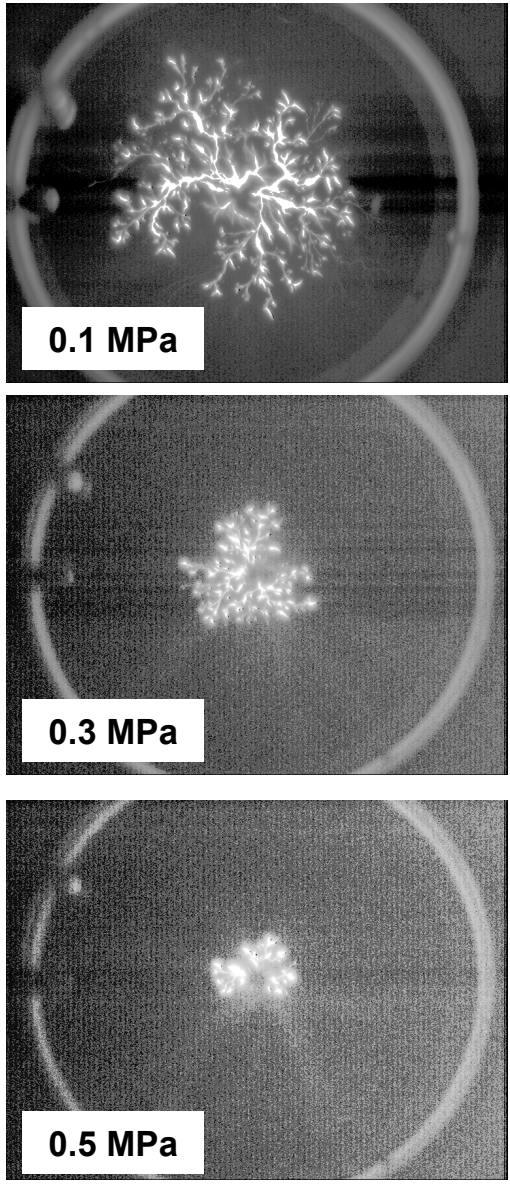

Figure 10. Photographs of positive creeping discharges propagating over Bakelite samples of $2 \mathrm{~mm}$ thickness for different values of hydrostatic pressure, the applied voltage being a lightning impulse the crest value of which is $U_{\text {crest }}=50 \mathrm{kV}$.

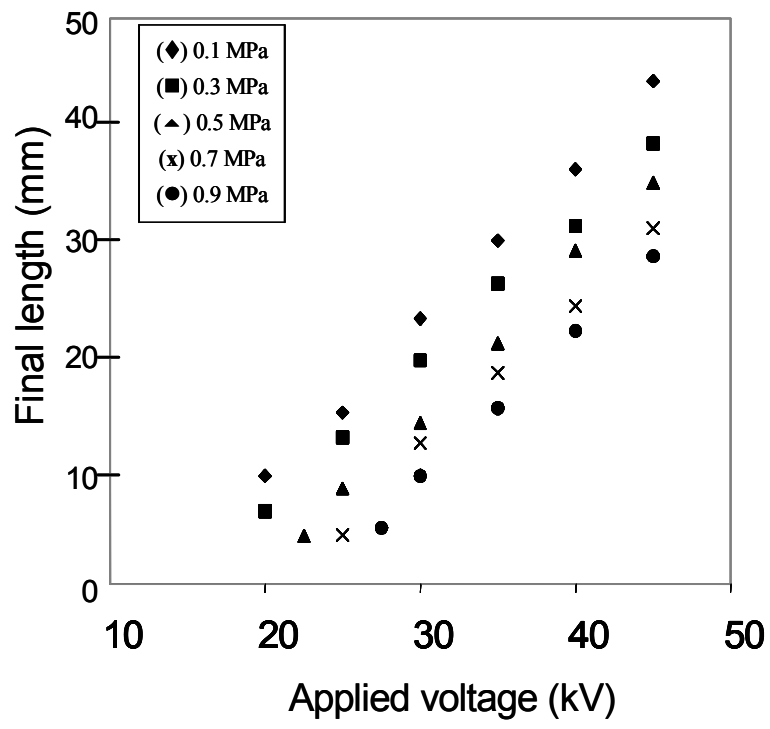

Figure 11. Final length $L_{f}$ of creeping discharges propagating over Bakelite samples of $8 \mathrm{~mm}$ thickness versus ac voltage for different pressures. 


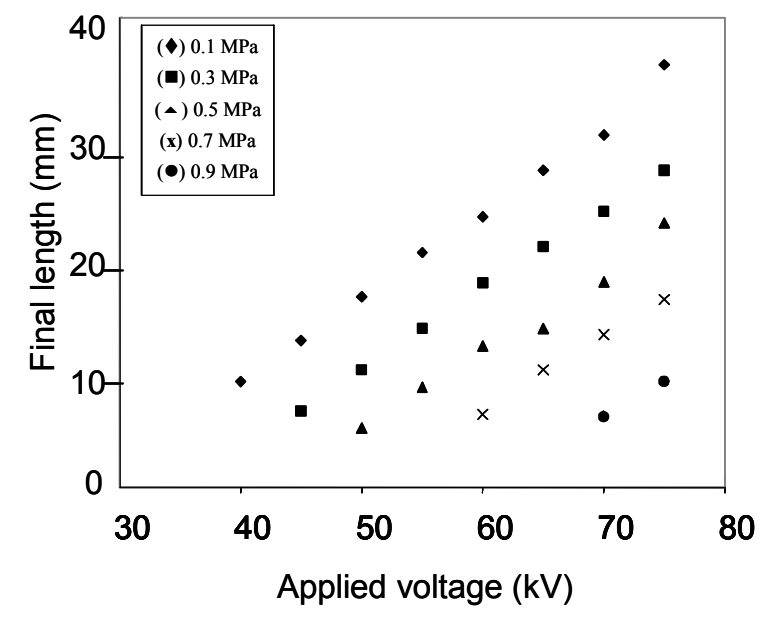

Figure 12. Final length $L_{f}$ of positive creeping discharges propagating over Bakelite samples of $8 \mathrm{~mm}$ thickness versus dc voltage for different pressures.
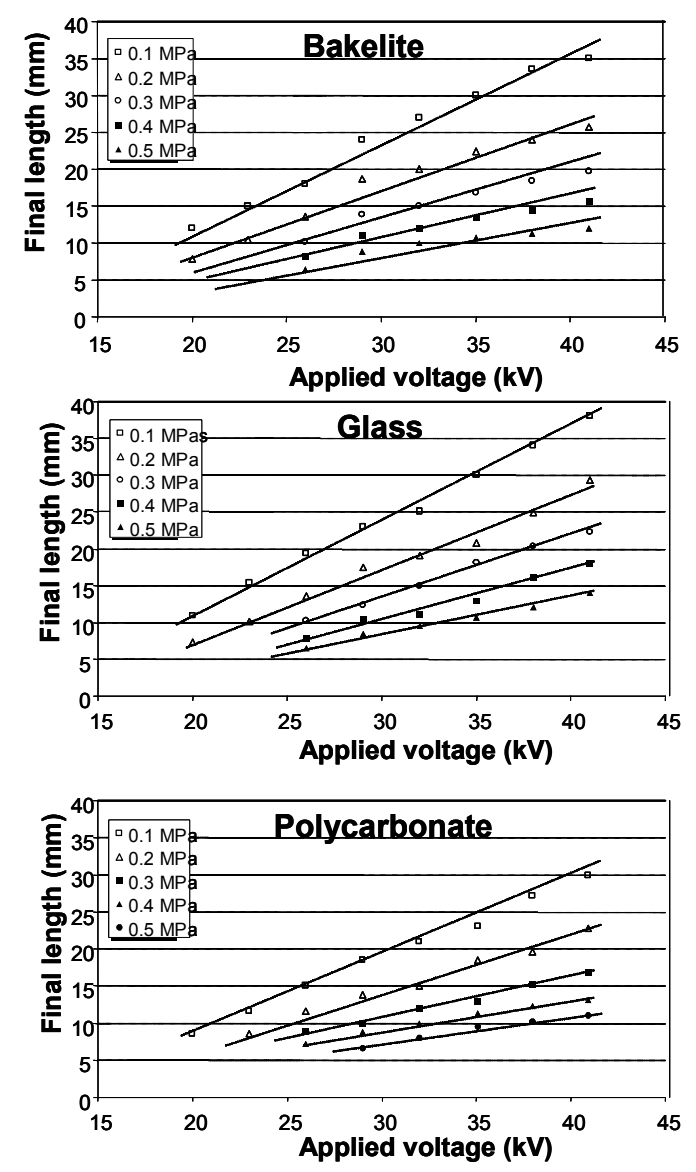

Figure 13. Final length $L_{f}$ of negative creeping discharges propagating over three kinds of solid samples of $2 \mathrm{~mm}$ thickness versus the crest value of lightning impulse voltage for different pressures.

In the same way, by plotting the final length of discharges $L_{f}$ versus the hydrostatic pressure $P$ for different voltage $U$, we observe that $L_{f}$ decreases quasi-linearly when $P$ is increased (Figures 15 and 16) except at $0.1 \mathrm{MPa}$, contrary to the observations reported in liquid dielectrics alone where $U$ is roughly proportional to the square root of the pressure $\left(\mathrm{P}^{-}\right.$ $\left.{ }^{0.5}\right)[11]$.
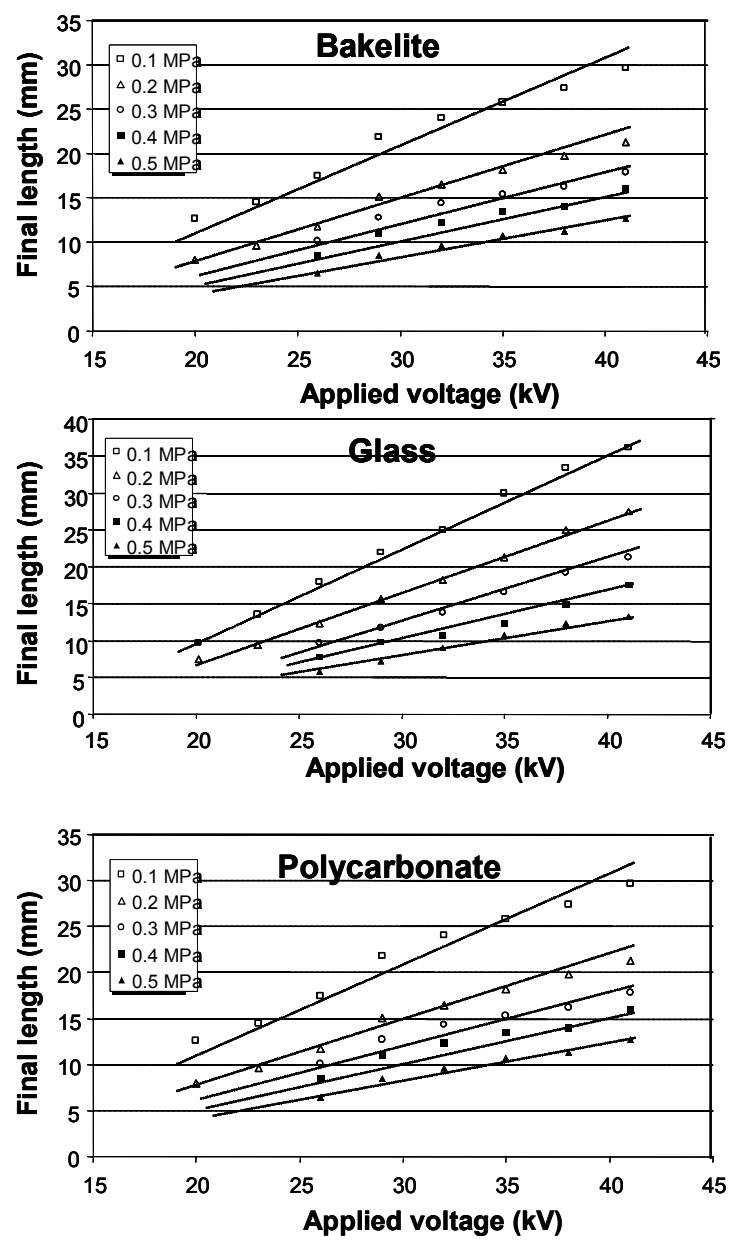

Figure 14. Final length $L_{f}$ of positive creeping discharges propagating over three kinds of solid samples of $2 \mathrm{~mm}$ thickness versus the crest value of lightning impulse voltage for different pressures.

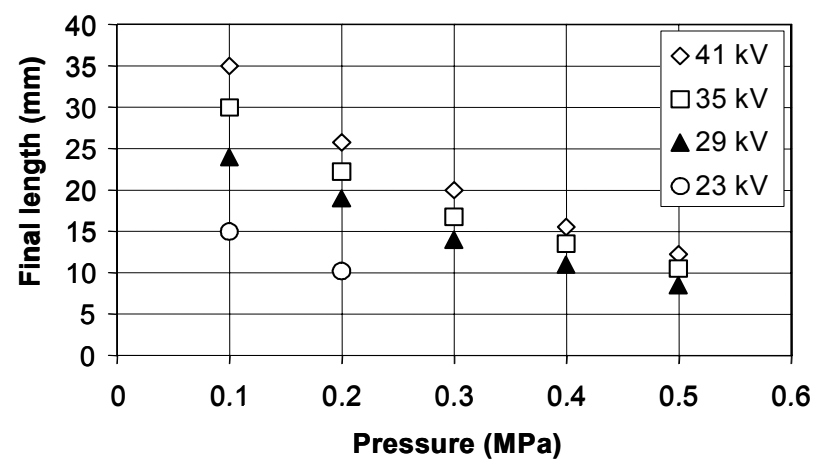

Figure 15. Final length $L_{f}$ of negative creeping discharge propagating over bakelite samples of $5 \mathrm{~mm}$ thickness for different crest values of lightning impulse voltage. 


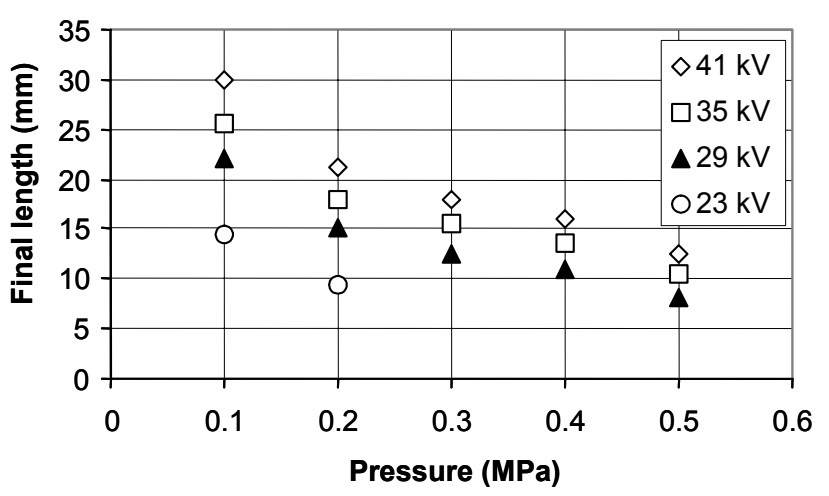

Figure 16. Final length $L_{f}$ of positive creeping discharge propagating over Bakelite samples of $5 \mathrm{~mm}$ thickness for different crest values of lightning impulse voltage.

And for given voltage $U$ and kind of interface, there is a pressure $P_{\text {disp }}$ for which the discharge disappears. $P_{\text {disp }}$ can be deduced by extrapolation at $L_{f}=0 \mathrm{~mm}$. The higher the voltage, the higher $P_{\text {disp }}$ is.

\section{CONCLUSION}

In this work, we showed that the characteristics of creeping discharges depend on the voltage waveform and the properties of solid insulator as well as the hydrostatic pressure; the influence of liquid has not been analyzed here. The threshold voltage required to initiate the creeping discharges are higher with dc than with ac and lightning impulse voltages. The negative discharges observed under lightning impulse voltages propagate radially while under ac and dc as well as with positive lightning impulse voltages, the discharges do not present a radial shape. For a given solid sample, the final length $L_{f}$ of discharges is higher with ac than with lightning impulse voltage and dc. $L_{f}$ increases quasi-linearly with the voltage. And the thinner the solid sample and/or the higher its dielectric constant, the longer the discharges are, whatever the voltage waveforms. This indicates the important role of the capacitive effects in the initiation and propagation processes of creeping discharges. Note that the current waveforms are similar to those observed in liquids.

The hydrostatic pressure acts on the creeping discharges by reducing the lengths of their branches and by increasing their initiation threshold voltage indicating the implication of gaseous mechanisms. The linear variation of the final length of discharge branches versus the voltage for a given pressure and versus the pressure for a given voltage whatever the polarity of voltage constitutes an original result which could be a useful tool for the dimensioning of solid / liquid insulating system in high voltage oil-filled apparatus.

\section{REFERENCES}

[1] J. C . Devins and S. J. Rzad, "Streamer Propagation in Liquids and over Liquid-Solid Interfaces", IEEE Conf. Electr. Insul. Dielectr. Phenomena (CEIDP), pp. 383-394, 1982.

[2] Y. Nakao, H. Itoh, Y. Sakai, and H. Tagashira, "Studies of the Creepage discharge on the Surface of liquids", IEEE Trans. Electr. Insul., Vol. 23, pp. 677-687, 1988.
[3] P. Atten and A. Saker, "Streamer propagation over a liquid/solid interface", IEEE Trans. Electr. Insul., Vol. 28, pp. 230-242, 1993.

[4] Y. Nakao, M. Naruse, H. Itoh, Y. Suzuki, Y. Sakai and H. Tagashira, "Influence of a Sort and a Thickness of Solid Insulators on the Propagation of the Positive Creepage Discharge in Transformer Oil", Trans. IEE of Japan, Vol. 116-A No. 10, pp. 849-854, 1996.

[5] Y. Nakao, K. Wakimoto, K. Miyagi, H. Itoh, Y. Sakai, and H. Tagashira, "Propagation Characteristics of Impulse Creepage Discharge in Perfluorocarbon Liquid", Electrical Engineering in Japan, Vol. 131, No. 4, pp. 19-28, 2000

[6] R. Hanaoka, T. Kohrin, T. Miyagawa and T. Nishi, "Creepage discharge characteristics over solid-liquid interfaces with grounded side electrode", IEEE Trans. Dielectr. Electr. Insul., Vol. 9, pp. 308-315, 2002.

[7] L. Kebbabi and A. Beroual, "Fractal analysis of creeping discharges propagating at solid/liquid interfaces: influence of the nature and geometry of solid insulators", J. of Phys. D: Appl. Phys., Vol. 39, pp. 177-183, 2006.

[8] L. Kebbabi and A. Beroual, "Optical and Electrical Investigations on Creeping Discharges over Solid/Liquid Interface under Lightning Impulse Voltage", IEEE Trans. Dielectr. Electr. Insul., Vol. 13, pp. 565-571, 2006.

[9] A. Beroual, M. Zahn, A. Badent, K. Kist, A.J. Schwabe, H. Yamashita, K. Yamazawa, M. Danikas, W.G. Chadb and Y. Torshin, "Propagation and Structure of Streamers in Liquid Dielectrics", IEEE Electr. Insul. Mag., Vol. 14, pp. 6-17, 1998.

[10] A. Beroual, "Electronic and gaseous processes in the prebreakdown phenomena of dielectric liquids", J. Appl. Phys., Vol. 73, pp. 45284533, 1993.

[11] A. Beroual and R. Tobazeon, "IEEE Conf. Electr. Insul. Dielectr. Phenomena (CEIDP), NAS - NRC, Buffalo, U.S.A, pp. 44-49, 1985.

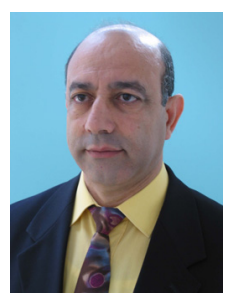

Abderrahmane Beroual (M'92) received the Dipl. Ing. and $\mathrm{Ph} . \mathrm{D}$. degrees in electrical engineering, respectively in 1976 from the Ecole Nationale Polytechnique of Algiers, Algeria and in 1979 from the Technical University of Wroclaw, Poland. In 1987, he obtained the Doctorat d'Etat ès Sciences Physiques degree from the Institut National Polytechnique of Grenoble, France. In 1980, he joined the Department of Electrical Engineering at the Ecole Nationale Polytechnique of Algiers. From 1983 to 1987, he was a researcher at the Laboratoire d'Electrostatique et de Matériaux Diélectriques (LEMD) CNRS of Grenoble, France and associate professor at the Joseph Fourier University of Grenoble. He received the title of professor at the Ecole Nationale Polytechnique of Algiers in 1987. In 1989, he joined the Ecole Centrale de Lyon, France where he is presently a professor and the head of the Dielectric Materials and High Voltage team at AMPERE Laboratory CNRS as well as Responsible of the Master Research Program in electrical engineering. He is responsible for numerous research projects. His main research interests include high voltage insulation, dielectric materials, outdoor insulation, long air discharge and lightning, modeling of discharges and composites. He is author/co-author of more than 280 papers and four patents. He supervised more than $30 \mathrm{Ph} . \mathrm{D}$. theses. He was the leader of the International Study Group on Streamer Propagation in Liquids of the IEEE DEIS (1994 - 1998). He serves on the Advisory Committees of International Conferences of ICDL, ISH, APTADM, Gas Discharge, ICHVE, CMD, INSUCON, NIWE and IREED.

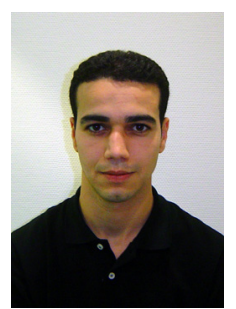

Lazhar Kebbabi was born in 1975 in Constantine, Algeria. He received the Dipl. Ing. and MS in electrical engineering, respectively in 2001 from the University of Constantine, Algeria, and in 2002 from Ecole Centrale de Lyon, France. In 2006, he obtained the Ph.D. degree from Ecole Centrale de Lyon. He presently works at Nexans company. His main research interests include high voltage and dielectric materials. 